\title{
CMA adopts patient focus
}

\author{
Cite as: CMAJ 2017 August 21;189:E1079. doi: 10.1503/cmaj.1095465
}

Posted on cmajnews.com on Aug. 3, 2017.

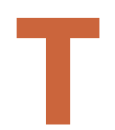

he Canadian Medical Association's (CMA's) new three-year strategy, CMA 2020, aims to make the organization more outward-facing and patient-focused.

The changes came after a period of soul-searching on what the purpose of the CMA was, and how it could best serve its members and the public, said Dr. Brian Brodie, chair of the board of directors. "We recognize that there are a lot of associations doctors belong to, and why would they pay to belong to different ones that do the same thing?" he said. "So it was important to look for opportunities for us to do something different."

While provincial medical associations are responsible for negotiating with provincial governments on behalf of their members, the national physician association does not share this job. This frees it to focus more on its roles in advocacy both for patients and doctors - and member services, said CMA President Dr. Granger Avery.

A focus on patients does not mean the association will be neglecting its members' needs, however. "The public is the reason we're serving as doctors," said Avery. "But the profession is equally a part of this - while we will put the public first, we will put doctors on the same level."

In many cases, the two overlap. "Part of advocacy for patients is advocacy for doctors," he said, for example, in the CMA's efforts to draw attention to and deal with physician burn-out. "If you don't have adequately maintained, properly trained, looked-after physicians, then we're not able to care for patients and the public."

Avery wants the association to work more collaboratively with all five health care partners: the profession, the government, health care managers, universities and the public. "If you don't have all five

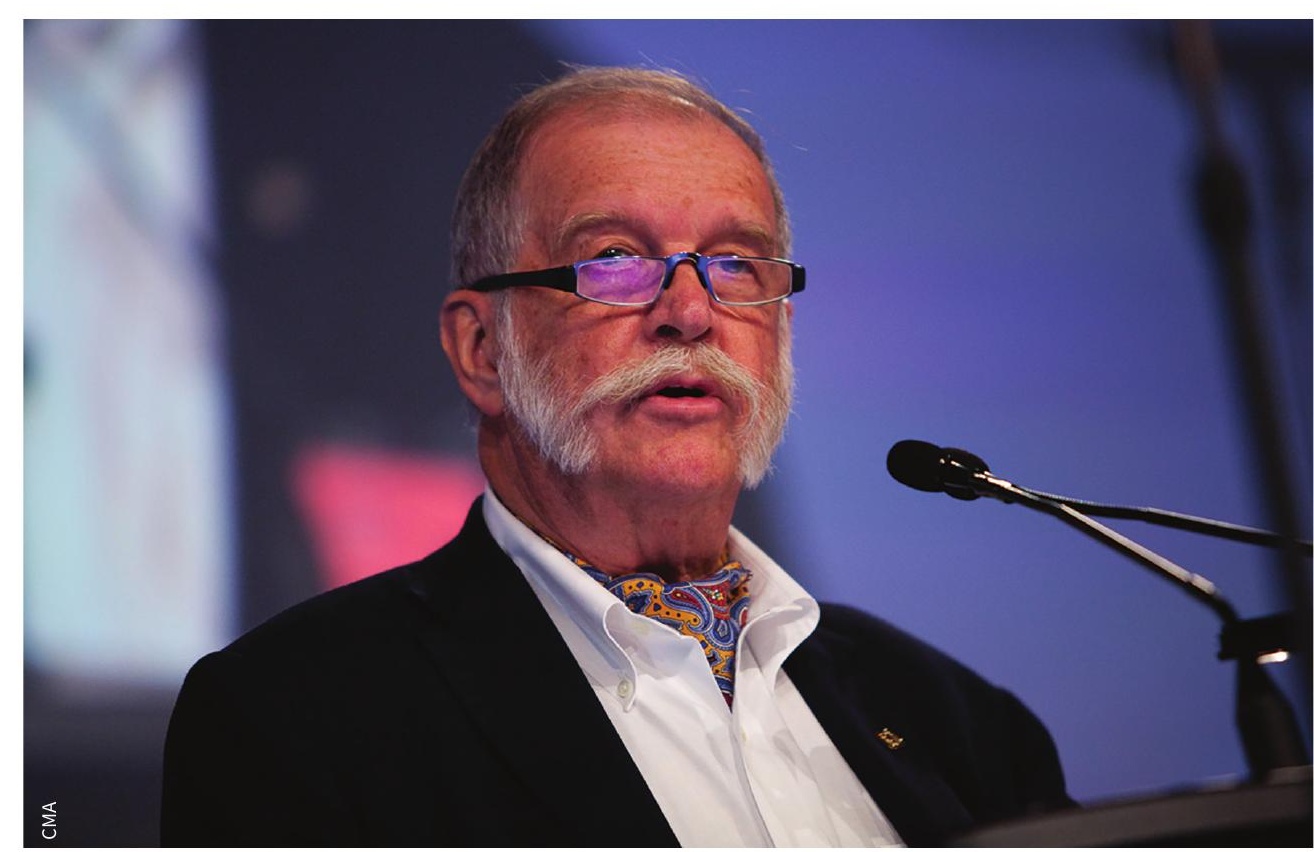

Advocacy for doctors is advocacy for patients, says CMA President Dr. Granger Avery.

partners, including patients, at the table, you're not going to get things done," he said. "We need to build relationships outside the profession."

That means finding ways to get patients involved in discussions, so that health care providers can learn what will really make a difference in their care. The CMA intends to work more closely with patient groups, as well as through campaigns targeting individual Canadians, such as the CMA's Demand a Plan campaign, which attracted 50000 signatures from people asking the government to adopt a national plan for seniors care. The association will also invite individual inputs from the public to its board and committees.

The goal is to shift from a member association to a more widely focused "social enterprise", says Avery. "This expands the idea that we're not just stamping out disease, it is actually our objective to make the whole population healthier and more productive," he said. "We need to expand beyond isolated medical interventions." CMA will continue to be a not-for-profit organization.

Dr. Sarah Gander, vice chair of Canadian Doctors for Medicare, is pleased that the CMA will be taking this broader view of health care. "It's nice to see the CMA recognizing that physicians have a powerful role in the social determinants of health," she said.

She hopes the association's new direction will include looking at what other forms of care could be brought together in a more coordinated system, including pharmacare, mental health, physiotherapy, dental care and more. "We need to treat the whole patient," she says.

Brian Owens, St. Stephen, NB 